\title{
PELAKSANAAN PELAYANAN KESEHATAN PESERTA BPJS PENERIMA BANTUAN IURAN DI PUSKESMAS MAMAJANG
}

\author{
The Implementation Of Health Services BPJS Kesehatan Registered In The Premium \\ Assistance Program In Mamajang Health Center
}

\author{
Rikardus Belang Meman ${ }^{1}$, Lusyana Aripa ${ }^{2}$, Kartini $^{3}$ \\ Fakultas Kesehatan Masyarakat Universitas Pancasakti Makassar
}

Korespondensi: rikardusbelangmeman@gmail.com

\begin{abstract}
ABSTRAK
Pelayanan kesehatan merupakan hak mendasar bagi masyarakat,oleh karena itu pelaksanaan program pelayanan kesehatan bagi peserta penerima bantuan iuranharusnya secara merata, karena dewasa ini masih kurangnya peserta penerima bantuan iuran merasakan program yang diberikan oleh pemerintah.Tujuan penelitian untuk mengetahui pelaksanaan pelayanan kesehatan pada peserta Badan Penyelenggara Jaminan Sosial (BPJS) Penerima Bantuan Iuran di Puskesmas Mamajang Kota Makassar. Jenis penelitian yang digunakan adalah penelitian kuantitatif observasional dengan metode deskriptif. Populasi dalam penelitian ini adalah Peserta BPJS Penerima Bantuan Iuran di Wilayah Kerja Puskesmas Mamajang dengan jumlah sampel sebanyak 100 responden. Teknik penarikan sampel dilakukan dengan cara purposive sampling dengan kriteria, responden yang sering menggunakan kartu Penerima Bantuan Iuran ketika berobat atau memeriksa kesehatan. Pengumpulan data dilakukan dengan wawancara langsung menggunakan kuesioner. Teknik analisis data menggunakan analisis deskriptif yang dituangkan dalam bentuk persentase.Hasil penelitian menunjukan bahwa jumlah kepesertaan dalam Pelayanan BPJS PBI yang sesuai sebanyak 66,0\% responden dan Pelayanan Kesehatan secara Promotif yang sesuai sebanyak 77,0\% responden, Preventif yang sesuai sebanyak $100 \%$, Kuratif yang sesuai sebanyak $100 \%$, dan Pelayanan Kesehatan secara Rehabilitatif yang sesuai sebanyak 100\%.Disarankan untuk pemerintah khususnya lembaga penyelenggara jaminan sosial untuk meningkatkan evaluasi serta sosialisasi agar pelaksanaan program BPJS PBI lebih merata untuk masyarakat miskin.
\end{abstract}

Kata Kunci: BPJS PBI, kepesertaan, pelayanan promotif, preventif, kuratif, rehabilitatif.

\section{ABSTRACT}

Health services are a fundamental right for the community, therefore the implementation of health care programs for participants who receive contribution assistance should be evenly distributed, because today there is still a lack of participants who receive contribution assistance feel the program provided by the government.The purpose of the study was to find out the implementation of health services in participants of the Social Security Administering Body (BPJS) Recipients of Contribution Assistance at the Mamajang Health Center in Makassar City..This study was quantitative observational research with the descriptive method. The population in this study was participants of BPJS Kesehatan registered in the Premium Assistance Program in the working area of Mamajang Health Center, Makassar with a total sample of 100 respondents. Samples were selected using a purposive sampling technique with certain criteria, namely, respondents often used the card of the Premium Assistance Recipient when seeking treatment or health checks. Data were collected through direct interviews using a questionnaire. After that, data were analyzed using descriptive analysis in the form of a percentage. It showed that the participation of respondents was $66.0 \%$ in the appropriate BPJS PBI services, $77.0 \%$ in the promotional health services, $100 \%$ in the preventive services, $100 \%$ in the curative services, and 100\% in the rehabilitative services.It is recommended for the government, especially social security providers, to improve evaluation and socialization so that the implementation of BPJS PBI program is more equitable for the poor.

Keywords: BPJS PBI, Participation, Promotional Services, Preventive, Curative, Rehabilitative. 


\section{PENDAHULUAN}

Pelayanan kesehatan merupakan salah satu hak mendasar masyarakat yang penyediaannya wajib diselenggarakan oleh pemerintah sebagaimana telah diamanatkan dalam Undang-undang Dasar 1945 pasal 28 H ayat (1) "Setiap orang berhak hidup sejahtera lahir dan batin, bertempat tinggal, dan mendapatkan lingkungan hidup yang baik dan sehat serta berhak memperoleh pelayanan kesehatan" dan Pasal 34 ayat (3) "Negara bertanggung jawab atas penyediaan fasilitas pelayanan kesehatan dan fasilitas pelayanan umum yang layak". Kesehatan merupakan salah satu investasi negara yang perlu diperhatikan, karena erat hubungannya dengan proses pembangunan sumber daya manusia yang sangat menentukan nasib bangsa. Oleh karena itu, pemerintah terus berupaya keras dalam rangka meningkatkan mutu kesehatan dengan membuat kebijakan-kebijakan dan penyediaan fasilitas untuk meningkatkan kualitas kesehatan masyarakat (Khafi, 2017).

Dalam mengatur masalah kesehatan diperlukan suatu badan khusus yang bertanggung jawab dalam menyelenggarakan jaminan kesehatan, dimana badan tersebut harus memberikan mutu pelayanan yang baik agar dapat tercapainya kepuasan pelayanan kesehatan. Di Indonesia telah didirikan suatu Badan Penyelenggara Jaminan Sosial Kesehatan yang selaras dengan tujuan Organisasi Kesehatan Dunia dalam mengembangkan jaminan kesehatan untuk semua penduduk. Kesehatan adalah hak asasi manusia dan unsur kesejahteraan yang harus di wujudkan sesuai cita-cita bangsa Indonesia sebagaimana dimaksud dalam Pancasila dan Pembukaan UUD 1945 (Hasyim et al., 2019).

Tingginya jumlah peserta BPJS (Badan Penyelenggara Jaminan Sosial) dari kategori PBI (Penerima Biaya Iuran), menunjukkan urgensi layanan kesehatan bagi kelompok masyarakat menengah ke bawah. Tingginya jumlah peserta BPJS dari kategori PBI juga menggambarkan bahwa tingginya kebutuhan layanan kesehatan bagi masyarakat miskin. Namun, pada kenyataannya akses layanan kesehatan yang baik masih menjadi permasalahan bagi masyarakat miskin di Indonesia (Nurmandhani \& Prasetyo, 2019).

Terkait dengan hal tersebut diatas, Puskesmas juga melaksanakan upaya-upaya kesehatan berupa Promotif, Preventif, Kuratif dan Rehabilitatif yang dilaksanakan secara menyeluruh, terpadu dan berkesinambungan dengan upaya tersebut diharapkan terwujud tujuan pembangunan kesehatan yaitu tercapainya kesadaran, kemauan dan kemampuan hidup sehat bagi setiap orang agar terwujud derajat kesehatan yang optimal (Depkes RI, 2012).

$$
\text { Dinas Kesehatan (Dinkes) Kota }
$$
Makassar mendaftarkan 160 ribu untuk masuk menjadi Peserta Bantuan Iuran (PBI) BPJS Kesehatan. Untuk Provinsi Sulawesi Selatan sendiri sebesar pengguna JKN sebanyak 4.301.539 peserta (46\%) Peserta PBI terdiri dari peserta dengan iuran bersumber dari APBN berjumlah 2.944.923 peserta dan yang 
bersumber dari ABPD berjumlah 47.934 peserta. Sedangkan peserta non PBI terdiri atas pekerja penerima upah berjumlah 820.528 peserta, pekerja bukan penerima upah berjumlah 249.555 peserta dan bukan pekerja berjumlah 238.599 peserta (Kemenkes RI, 2015 dalam Kurniawan, 2018).

Berdasarkan data awal yang dilakukan oleh peneliti maka di dapatkan data bahwa laporan tahunan khususnya di Puskesmas Mamajang Kota Makassar ini terlihat bahwa kunjungan di tahun 2017 sebanyak 61.155 orang. Pada tahun 2018 mengalami penurunan menjadi 56.013 orang. Dan pada tahun 2019 meningkat menjadi 15.808 .000 orang. Jumlah kunjung perbulan \pm 4000 pasien. Untuk penerima bantuan iuran khususnya di kecamatan mamajang terdaftar 5000 jiwa. Cakupan wilayah kerja Puskesmas Mamajang terdapat 6 Kelurahan yakni : Labuan Baji, Mamajang luar, Mamajang dalam, Bonto Biraen, Maricaya, dan Mandala dengan jumlah penduduk rata-rata 21.421 jiwa.

\section{BAHAN DAN METODE}

Desain yang digunakan dalam penelitiaan ini adalah deskriptif kuantitatif. Peneliti menguji data pada satu titik waktu dan data dikumpulkan hanya pada satu kesempatan dengan subyek yang sama. Penelitian ini dilaksanakan pada bulan September-November 2020 di Puskesmas Mamajang kecamatan Mamajang Kota Makassar. Populasi dalam penelitian ini adalah masyarakat yang tinggal di wilayah kerja PKM Mamajang yang sering menggunakan kartu PBI (penerima bantuan iuran) ketika berobat dan memeriksa kesehatan. yang berjumlah 5000 peserta. Pada penelitian ini sampel diambil dengan menggunakan teknik non probality sampling (Purposive sampling), besar sampelnya berjumlah100 responden dengan menggunakan analisis univariat. Data diproleh melalui pembagian kuisioner kepada responden pada saat penelitian yang disesuaikan dengan tujuan penelitian, serta diproleh dari pencatatan dan pelaporan atau dokumentasi berupa catatan yang ada di Puskesmas Mamajang. Teknik pengolahan data yang telah diperoleh dari kuesioner pada penelitian ini adalah menggunakan komputer program SPSS dan data tersebut kemudian diolah dengan prosedur pengolahan data.

\section{HASIL}

\section{Karakteristik Responden}

Tabel 1 menunjukkan bahwa distribusi responden yang berjenis kelamin laki-laki peserta BPJS PBI berjumlah 54 orang (54.0\%), sedangkan yang berjenis kelamin perempuan berjumlah 46 orang (46.0\%). Dari distribusi umur responden peserta BPJS PBI paling tinggi 20-35 tahun sebanyak 42 (42.0\%), dan yang terendah dari umur 46-50 tahun sebanyak $10(10.0 \%)$ orang. Distribusi dilihat dari tingkat pendidikan responden peserta BPJS PBI paling tinggi tingkat SMA sebanyak 48 (48.0\%), dan terendah tingkat SMP sebanyak $12(12,0 \%)$ Serta dari distribusi responden menurut pekerjaan peserta BPJS PBI yang tertinggi yaitu ibu rumah tangga sebanyak 44 orang $(44,0 \%)$, dan terendah yang bekerja 
http://journal.unpacti.ac.id/index.php/JPP

sebagai wiraswasta/swasta yaitu sebanyak 20 orang $(20.0 \%)$.

Tabel 1. Karateristik Responden

\begin{tabular}{lcc}
\hline \multicolumn{1}{c}{ Karakteristik } & n & $\mathbf{\%}$ \\
\hline Jenis kelamin & & \\
$\quad$ Laki-laki & 54 & 54.0 \\
$\quad$ Perempuan & 46 & 46.0 \\
Umur & & \\
20-35 Tahun & 42 & 42.0 \\
36-45 Tahun & 25 & 25.0 \\
$\quad$ 46-50 Tahun & 10 & 10.0 \\
$\quad$ >50 Tahun & 23 & 23.0 \\
Pendidikan & & \\
$\quad$ SD & 40 & 40.0 \\
$\quad$ SMP & 12 & 12.0 \\
$\quad$ SMA & 48 & 48.0 \\
Pekerjaan & & \\
$\quad$ Wiraswasta/Swasta & 20 & 20.0 \\
$\quad$ Buru & 36 & 36.0 \\
$\quad$ Ibu Rumah Tangga & 44 & 44.0 \\
Jumlah & 100 & 100 \\
\hline Sumb Data Prim, 2020 & &
\end{tabular}

Sumber: Data Primer, 2020

Analisis Univariat

Tabel 2 menunjukan bahwa kepesertaan dalam program pelayanan BPJS PBI yang sesuai sebanyak 66 (66.0\%). Sedangkan pada peserta BPJS PBI yang tidak sesuai sebanyak 34 (34.0\%).

Pada pelayanan promotif untuk peserta BPJS PBI yang sesuai sebanyak 77 $(77.0 \%)$ yaitu memberikan pelayanan kesehatan kepada masyarakat sesuai kebutuhannya, memberikan konsultasi kesehatan kepada ibu hamil, balita, lansia, dan penyuluhan kesehatan, pemeliharaan, dan peningkatan kesehatan. Dan pelayanan promotif untuk peserta BPJS PBI yang tidak sesuai sebanyak $23(23.0 \%)$ yaitu tidak tersedianya fasilitas kesehatan dalam bentuk (gedung olahraga dan alat-alat olahraga) dan tidak dilakukan senam pagi secara rutin.

Tabel 2 Distribusi Program Pelayanan BPJS PBI

\begin{tabular}{|c|c|c|}
\hline $\begin{array}{l}\text { Distribusi Program } \\
\text { Pelayanan BPJS PBI }\end{array}$ & (n) & $\%$ \\
\hline \multicolumn{3}{|l|}{ Kepesertaan } \\
\hline Sesuai & 66 & 66.0 \\
\hline Tidak Sesuai & 34 & 34.0 \\
\hline \multicolumn{3}{|l|}{$\begin{array}{l}\text { Pelayanan kesehatan } \\
\text { (promotif) }\end{array}$} \\
\hline Sesuai & 77 & 77.0 \\
\hline Tidak Sesuai & 23 & 23.0 \\
\hline \multicolumn{3}{|l|}{$\begin{array}{l}\text { Pelayanan kesehatan } \\
\text { (preventif) }\end{array}$} \\
\hline Sesuai & 100 & 100,0 \\
\hline \multicolumn{3}{|l|}{$\begin{array}{l}\text { Pelayanan kesehatan } \\
\text { (kuratif) }\end{array}$} \\
\hline Sesuai & 100 & 100.0 \\
\hline \multicolumn{3}{|l|}{$\begin{array}{l}\text { Pelayanan kesehatan } \\
\text { (Rehabilitatif) }\end{array}$} \\
\hline Sesuai & 100 & 100.0 \\
\hline Jumlah & 100 & 100 \\
\hline
\end{tabular}

BPJS PBI yang sesuai sebanyak 100 (100,0\%) yaitu dilihat dari kegiatan seperti melakukan pemeriksaan kesehatan secara berkala pada balita, ibu hamil, remaja dan usia lanjut.

Pelayanan Rehabilitatif dalam program pelayanan BPJS PBI yang sesuai sebanyak 100 $(100,0 \%)$ yaitu dilihat dari pemulihan keadaan pascasakit pada bayi, balita, ibu hamil, dan lansia. Adapun yang lainnya yaitu memperbaiki gizi kesehatan pada anak yang kurang gizi seperti pemberian MP-ASI, memberikan motivasi dan kepercayaan diri bagi penderita penyakit tertentu, memberikan latih nafas dan latihan batuk pada penderita $\mathrm{TBC}$, dan melakukan penyuluhan dan usaha- 
usaha kelanjutan kepada pasien yang sembuh dari suatu penyakit.

\section{PEMBAHASAN}

\section{Kepesertaan}

\begin{abstract}
Kepesertaan adalah peserta BPJS
khusus penerima bantuan iuran, yang tergolong fakir miskin dan masyarakat tidak mampu. Kriteria fakir miskin dan orang tidak mampu ditetapkan oleh menteri di bidang sosial setelah berkoordinasi dengan menteri dan atau pimpinan lembaga terkait dan penetapan jumlah PBI jaminan kesehatan pada tahun 2014 dilakukan dengan menggunakan hasil pendataan Program Perlindungan Sosial tahun 2011.
\end{abstract}

Hasil penelitian ini menunjukkan bahwa dalam program pelayanan BPJS PBI yang sesuai sebanyak $66(66,0 \%)$ itu dilihat dari jenis lantai tempat tinggalnya masih beralaskan lantai kasar, papan atau kayu murahan, dinding rumah terbuat dari kayu berkualitas rendah, dan tembok tanpa dipelester dalam seminggu hanya mengkonsumsi daging,susu,ayam hanya sekali serta tidak sanggup membayar pengobatan di puskesmas. Sedangkan pada peserta BPJS PBI yang tidak sesuai sebanyak $34(34.0 \%)$ yaitu dari keluarga yang memiliki rumah yang terbuat dari tembok, selalu menggunakan sumber air PAM, untuk memasak sehariharinya menggunakan kompor gas, dan juga selalu mengkonsumsi daging, susu lebih dari satu kali seminggu serta sanggup untuk membayar biaya pengobatan dipuskesmas atau poliklinik.

Pada penelitian ini menunjukan bahwa masih banyak peserta BPJS penerima bantuan iuran (PBI) di Puskesmas Mamajang Kota Makassar yang bukan termasuk kategori keluarga miskin atau tidak mampu tetapi sudah terdaftar dalam kepesertaan BPJS PBI hal ini terjadi dikarenakan petugas atau pemerintah setempat tidak mendapatkan data yang begitu akurat pada saat pendataan bagi keluarga yang tidak mampu. Adapun faktor lain dalam hal ini yaitu faktor kekeluargaan, biasanya petugas pendataan memasukan nama keluarganya untuk mendapatkan pelayanan BPJS PBI meskipun masyarakat tersebut dikategorikan mampu sehingga penerapan BPJS PBI ini tidak merata.

Penelitian ini sejalan dengan penelitian Pratiwi R (2015) di RSUD Prof. Dr. Aloei Saboe Kota Gorontalo yang menemukan bahwa dari 430 responden yang sesuai dengan kepesertaan BPJS PBI sebanyak 200 orang $(46,2 \%)$. Hal itu dilihat dari jenis tempat tinggal terbuat dari kayu dan masih berlantai tanah dan tidak menggunakan penerangan seperti listrik. Sedangkan yang tidak sesuai pada kepesertaan BPJS PBI sebanyak 230 orang $(53,4 \%)$. Hal ini terjadi dikarenakan masih banyak petugas atau pemerintah setempat tidak mendapatkan data keluarga yang tergolong kurang mampu tidak begitu akurat.

Penelitian lain juga dilakukan oleh Rosdiana W (2016) dengan judul Implementasi 
Program jaminan kesehatan nasional (PBI) dan

Non PBI di Puskesmas Kokop Kecamatan

Kokop kabupaten Bangkalan dari 450 responden yang terdaftar di BPJS PBI yang sesuai sebanyak 280 orang $(65 \%)$ dan yang tidak sesuai sebanyak 170 orang (35\%).

Hasil penelitian Khafi menyatakan bahwa pelaksanaan jaminan kesehatan di RS dan puskesmas rujukan masih mengabaikan terkait pelayanan yang berkualitas dan pelayanan administrasi masih ada yang berbelit-belit meskipun tidak separah dulu akan tetapi untuk pelayanan kesehatannya beberapa masih ditemukan perbedaan pelayanan terhadap pasien BPJS PBI dan mengabaikan kesamaan hak setiap orang mendapatkan pelayanan kesehatan yang baik dan tanpa diskriminasi.

Menurut hasil penelitian dari Prayogi, (2018) menemukan bahwa pelaksanaan kualitas pelayanan progam JKN- PBI tidak maksimal diberikan oleh fasilitas kesehatan, seperti pembiayaan tambahan dalam menebus obat, penambahan biaya untuk melakukan test laboratorium, lambannya pemeriksaan pasien JKN-PBI, dan prosedur admintrasi yang lama dan antrian panjang dalam pemeriksaan kesehatan.

Dari hasil penelitian bisa disimpulkan bahwa Implementasi BPJS PBI di Puskesmas Mamajang Kota Makassar tidak merata, masih banyak masyarakat yang tergolong fakir miskin dan tidak mampu belum terdaftar di BPJS PBI, masih ada perbedaan pelayanan terhadap peserta BPJS PBI. Ketidaktahuan masyarakat akan syarat ataupun prosedur dalam pendaftarannya menjadi peserta BPJS PBI menjadi kendala akan penerapan program pelayanan BPJS PBI yang tidak merata dan kurangnya sosialisasi dari pemerintah setempat sehingga masih banyak masyarakat miskin beranggapan bahwa iuran BPJS PBI tidak dibayar oleh pemerintah.

\section{Pelayanan Promotif}

Upaya promotif dilakukan untuk meningkatkan kesehatan individu, keluarga, kelompok dan masyarakat. Setiap individu berhak untuk menentukan nasib sendiri, mendapat informasi yang cukup dan untuk berperan di segala aspek pemeliharaan kesehatannya (Depkes RI 2009).

Hasil penelitian ini menunjukan bahwa pelayanan promotif untuk peserta BPJS PBI yang sesuai sebanyak $77(77.0 \%)$ yaitu memberikan pelayanan kesehatan kepada masyarakat sesuai kebutuhannya, memberikan konsultasi kesehatan kepada ibu hamil, balita, lansia, serta adanya penyuluhan kesehatan, pemeliharaan, dan peningkatan kesehatan. Sedangkan pelayanan promotif untuk peserta BPJS PBI yang tidak sesuai sebanyak 23 (23.0\%) yaitu dilihat dari tidak adanya penyediaan fasilitas kesehatan seperti gedung dan tempat olahraga serta tidak adanya kegiatan olahraga atau senam secara rutin.

Hal ini sama dengan hasil penelitian yang dilakukan oleh Ratih Kumala Dewi (2018) mengenai Identifikasi Pelayanan Promotif pada fasilitas kesehatan pertama program Jaminan Kesehatan Nasional PBI di 
Puskesmas Tlogosari Wetan Semarang didapatkan hasil bahwa yang tidak sesuai dalam pelayanan promotif yaitu tidak adanya kegiatan olahraga atau senam secara rutin sebanyak (56\%).

Senada dengan itu, penelitian yang dilakukan oleh Riyadi R (2015) tentang Mutu pelayanan kesehatan bagi peserta BPJS PBI di Puskesmas Kembangan dengan hasil masih ada kegiatan pelayanan promotif yang tidak sesuai yaitu dari tidak adanya penyediaan fasilitas kesehatan dalam bentuk gedung olahraga dan kegiatan senam secara rutin yaitu sebanyak $(45,5 \%)$.

Berdasarkan data tersebut diatas bahwa tidak ada fasilitas kesehatan seperti gedung dan alat olahraga yang di siapkan khusus untuk masyarakat. Hal ini yang nantinya akan berpengaruh pada tingkat kesadaran dan pemahaman masyarakat akan pentingnya olahraga dan senam bagi kesehatan tubuh agar terhindar dari penyakit.

\section{Pelayanan Preventif}

Preventif Adalah sebuah usaha yang dilakukan individu dalam mencegah terjadinya sesuatu yang tidak diinginkan atau tindakan pencegahan terhadap ganguan yang bisa mengancam pribadi atau kelompok atau melakukan berbagai tindakan untuk menghindari terjadinya masalah kesehatan yang mengancam diri kita sendiri dengan orang lain dimasa yang akan datang.

Hasil penelitian ini menunjukan bahwa pelayanan Preventif untuk peserta BPJS PBI yang sesuai sebanyak $100(100,0 \%)$ yaitu dilihat dari kegiatan seperti melakukan pemeriksaan kesehatan secara berkala pada balita, ibu hamil, remaja dan usia lanjut. Adapun yang lainnya seperti pemberian vitamin A, yodium, melalui posyandu, puskesmas, maupun dirumah, memberikan imunisasi terhadap bayi dan anak balita serta ibu hamil, dan melakukan pemeriksaan kehamilan, nifas ( masa selama melahirkan ) dan menyusui. Dan adanya penyediaan cuci tangan atau antiseptic di puskesmas.

Hasil penelitian ini tidak sejalan dengan yang dilakukan oleh Riyadi R (2015) tentang mutu pelayanan kesehatan peserta BPJS PBI di Puskesmas kembangan Jakarta Barat dengan hasil analisis statistik deskriptif bahwa $38 \%$ kegiatan pelayanan preventif yang tidak sesuai. Sedangkan yang sesuai sebanyak $62 \%$.

\section{Pelayanan Kuratif}

Upaya kuratif adalah upaya kesehatan untuk mencegah penyakit menjadi lebih parah melalui pengobatan. Sasarannya adalah kelompok orang sakit (pasien) terutama penyakit kronis sperti asma, DM, TBC, rematik, hipertensi dan sebagainya. Upaya kuratif bertujuan untuk merawat dan mengobati anggota keluarga, kelompok yang menderita penyakit atau masalah kesehatan.

Hasil penelitian ini menunjukan bahwa pelayanan Kuratif pada peserta BPJS PBI yang sesuai sebanyak $100 \quad(100.0 \%)$ yaitu puskesmas melakukan perawatan tindak lanjut kepada orang sakit, melakukan pemberian obat seperti vitamin A, oralit, dan zat besi serta memberikan pelatihan fisik tertentu bagi 
penderita penyakit seperti TBC dan juga STROKE, melakukan pemeriksaan secara rutin (paru-paru,darah,dll ), melakukan pemberian obat (vitamin A,oralit, dan zat besi), melakukan pengobatan secara rutin.

Tidak sejalan dengan penelitian lain yang dilakukan oleh Rosdiana W (2015) tentang Implementasi program JKN bagi peserta PBI dan Non PBI dipuskesmas Kokop kabupaten Bangkalan dengan hasil analisis deskriptif $57 \%$ kegiatan pelayanan kesehatan dari pelayanan kuratif dilihat dari dilakukannya perawatan tindak lanjut kepada orang sakit sedangkan yang tidak sesuai sebanyak $43 \%$ yaitu dari tidak adanya dukungan psikis penderita TBC,STROKE,dan HIV AIDS.

\section{Pelayanan Rehabilitatif}

Rehabilitatif adalah usaha untuk mengembalikan bekas penderita kedalam masyarakat, sehingga dapat berfungsi sebagai anggota masyarakat yang berguna untuk dirinya dan masyarakat, semaksimalnya sesuai dengan kemampuannya.

Hasil penelitian ini menunjukan bahwa pelayanan rehabilitatif dalam program pelayanan BPJS PBI yang sesuai sebanyak 91 $(100,0 \%)$. Hal ini dilihat dari pemulihan keadaan pasca sakit pada bayi, balita, ibu hamil, dan lansia. Adapun yang lainnya yaitu memperbaiki gizi kesehatan pada anak yang kurang gizi seperti pemberian MP-ASI, memberikan latihan nafas dan latihan batuk pada penderita TBC, memberikan dukungan moril kepada penderita penyakit, melakukan usaha lanjutan kepada pasien yang sembuh dari suatu penyakit.

Hasil penelitian ini tidak sejalan dengan penelitian yang dilakukan Riyadi $\mathrm{R}$ (2015) tentang mutu pelayanan kesehatan peserta BPJS PBI dipuskesmas Kembangan dengan hasil analisis statistik bahwa pelayanan rehabilitatif untuk peserta BPJS PBI yang sesuai sebanyak $34 \%$ dan yang tidak sesuai sebanyak 66

\section{KESIMPULAN DAN SARAN}

Hasil penelitian ini menunjukan bahwa peserta BPJS PBI yang tidak sesuai yaitu dari keluarga yang memiliki rumah yang terbuat dari tembok, untuk memasak sehari-harinya menggunakan kompor gas, dan juga selalu mengkonsumsi daging, susu lebih dari seminggu serta sanggup untuk membayar biaya pengobatan dipuskesmas atau poliklinik. Pelayanan promotif untuk peserta BPJS PBI yang tidak sesuai yaitu dilihat dari penyediaan fasilitas kesehatan seperti gedung dan tempat olahraga serta tidak adanya kegiatan olahraga atau senam secara rutin. Pelayanan preventif untuk peserta BPJS PBI di puskesmas Mamajang yang sesuai yaitu kegiatan seperti melakukan pemeriksaan kesehatan secara berkala pada balita, ibu hamil, remaja dan usia lanjut. Adapun yang lainnya seperti pemberian vitamin A, yodium, melalui posyandu, puskesmas, maupun dirumah, memberikan imunisasi terhadap bayi dan anak balita serta ibu hamil, dan melakukan pemeriksaan kehamilan, nifas dan menyusui. Dan adanya 
penyediaan cuci tangan atau antiseptic di puskesmas.

Pelayanan kuratif untuk peserta BPJS PBI yang sesuai yaitu dilihat puskesmas melakukan perawatan tindak lanjut kepada orang sakit, melakukan pemberian obat seperti vitamin A, oralit, dan zat besi serta memberikan pelatihan fisik tertentu bagi penderita penyakit seperti TBC dan juga STROKE, melakukan pemeriksaan secara rutin (paru-paru, darah, dll), melakukan pemberian obat (vitamin A,oralit, dan zat besi), melakukan pengobatan secara rutin.

Dan pelayanan rehabilitatif untuk peserta BPJS PBI yang sesuai dilihat dari pemulihan keadaan pasca sakit pada bayi,balita, ibu hamil,dan lansia, adapun yang lainnya yaitu memperbaiki gizi kesehatan pada anak yang kurang gizi seperti pemberian MPASI, memberikan latihan nafas dan latihan batuk pada penderita TBC, memberikan dukungan moril kepada penderita penyakit, melakukan usaha lanjutan kepada pasien yang sembuh dari suatu penyakit.

Disarankan kepada kepala puskesmas Mamajang dan Dinas Kesehatan Kota Makassar perlu melakukan pemantauan evaluasi kembali terkait dengan kepesertaan dan memberikan sosialisasi kepada masyarakat akan syarat atau prosedur menjadi peserta BPJS PBI, sehingga penerapan pelayanan kesehatan terhadap peserta BPJS PBI merata. Bagi pemerintah khususnya lembaga yang menyelenggarakan jaminan sosial atau BPJS dapat lebih giat untuk melakukan evaluasi serta Sosialisasi agar pelaksanaan program BPJS PBI (penerima bantuan Iuran) lebih merata untuk masyarakat miskin.

\section{DAFTAR PUSTAKA}

Depkes, RI 2012. Peraturan Mentri Kesehatan Indonesia

Hasyim, A., Idrus, H. M., \& Rizky, S. (2019). Faktor-Faktor Yang Berhubungan Dengan Penunggakan Pembayaran Iuran Bpjs Kesehatan Mandiri Di Wilayah Kerja Puskesmas Abeli Kota Kendari. 2(1),

Kaha. (2017) Pelaksanaan Program Pelayanan Kesehatan Pada Peserta Bpjs (Badan Penyelenggara Jaminan Sosial) Penerima Bantuan Iuran Di Puskesmas Ritaebang Kecamatan Solor Barat Kabupaten Flores Timur. Universitas Pancasakti

Kementrian Kesehatan RI, Buku Pegangan Sosialisasi Jaminan Kesehatan Nasional (JKN) dalam Sistem Jaminan Sosial Nasional, (Jakarta: Sekretaris Jenderal Kementrian Kesehatan RI, 2013), h 1719

Khafi, M. S. (2017). Pelaksanaan Jaminan Kesehatan Bagi Penerima Bantuan Iuran (Pbi) Oleh Badan Penyelenggara Jaminan Sosial (Bpjs) Kota Yogyakarta Dan Rumah Sakit Umum Daerah (Rsud) Wonosari [Universitas Islam Negeri Sunan Kalijaga Yogyakarta].Https://Doi.Org/10.1037/00 22-3514.51.6.1173

Kurniawan, D. (2018). Faktor Faktor Yang Mempengaruhi Masyarakat Dalam Pemanfaatan Jaminan Kesehatan Nasional Di Wilayah Kerja Puskesmas Tamalanrea Jaya Kota Makassar. Universitas Hasanuddin Makassar.

Nurmandhani, R., \& Prasetyo, I. (2019). Pelaksanaan Program "Rsud Kajen Berbagi" Sebagai Upaya Pelayanan 
http://journal.unpacti.ac.id/index.php/JPP

Kesehatan Gratis Di Rsud Kajen

Kabupaten Pekalongan. 14(November).

Prayogi, P. (2018). Pemerintah dan Rumah Sakit Swasta: Studi Kebijakan Progam Jaminan Kesehatan Nasional - Penerima Bantuan Iuran di Kabupaten Sidoarjo.

Riyadi, R. (2016). Mutu Pelayanan Kesehatan Peserta Jaminan Kesehatan Nasional Di
Puskesmas Kecamatan Kembangan Jakarta Barat Skripsi. Universitas Islam Negeri Syarif Hidayatullah Jakarta 1436

Rosdiana, W. (2015). Implementasi Program Jaminan Kesehatan Nasional Pemberian Bantuan Iuran Di Puskesmas Kokop Kecamatan Kokop Kabupaten Bangkalan. 